\title{
A Responsabilidade Civil No Direito Ambiental Brasileiro
}

\section{RESUMO}

O Direito assumiu papel preponderante na gestão dos riscos na sociedade contemporânea definida, por muitos autores, como de Risco; com isso, novos direitos foram instituídos e novos instrumentos e meios de tutela foram criados. A responsabilidade civil ambiental tornou-se um dos principais instrumentos criado para a gestão do risco ambiental e tem-se harmonizado com a nova realidade marcada por incertezas científicas, riscos e danos globais. $\mathrm{O}$ objetivo deste trabalho foi analisar a responsabilidade civil ambiental no Direito brasileiro e contribuir para o seu desenvolvimento e debate. Utilizou-se o método de pesquisa monográfico e as técnicas de pesquisa bibliográfica e documental. Conclusões: (i) o resultado de uma conduta deve ser compreendido como dano futuro, risco de dano ou dano efetivo; portanto, não somente este; (ii) a Teoria do Risco Integral, por conseguinte, a adoção da Teoria da Equivalência das Condições na avaliação do nexo causal revela-se a mais adequada para a proteção do ambiente no contexto presente; (iii) a responsabilidade civil ambiental está apta a combater danos e a geração de riscos, se for adotada a Teoria do Risco Integral e se houver a imposição de adstreintes para coibir a prática de condutas lesivas.

\section{Palavras-chave}

Dano Futuro; Meio Ambiente; Responsabilidade Civil; Risco.

( $\left.^{\star}\right)$ Doutora em Direito, professora Adjunta da Universidade Federal de Pelotas. E-mail: <silvi_henkes@ hotmail.com>. Recebido em 22.11.08. Reapresentado em 29.01.09. Aprovado em 03.02.09. 


\begin{abstract}
Law has assumed a predominant role in the risk management at the contemporary society, defined by many authors as a society of Risk. With that, new rights were set up and new instruments and ways of protection were created. The civil environmental responsibility has become one of the main instruments created to the management of environmental risks and it has been harmonizing with this new reality which is marked by scientific uncertainties, risks and global damages. This work intends to analyse the civil environmental responsibility in the Brazilian Law in order to contribute to its development and discussion. It was used the monographic method of research and the bibliographical and documentary inquiry techniques. Conclusions: (i) the result of a conduct must be understood as future damage, risk of damage or effective damage, and not only the last one; (ii) the Theory of Integral Risk and, consequently, the adoption of Theory of Equivalence of Conditions in the evaluation of the causal nexus are most adequate to the protection of the environment in the present context; (iii) the civil environmental responsibility is suitable to fight against damages and the generation of risks, if the Theory of the Integral Risk is adopted and there is the imposition of daily fines to restrict the practice of harmful conducts.
\end{abstract}

\title{
Keywords
}

Environment; Future Damage; Responsibility; Risk.

\section{INTRODUÇÃO}

A partir da década de 1970, século XX, com a eclosão de grandes problemas $^{(1)}$ e catástrofes ambientais ${ }^{(2)}$, assim como o aparecimento e desenvolvimento de novas doenças e vírus ${ }^{(3)}$, a análise da sociedade sob o

(1) A escassez de recursos naturais, como a água potável; a desertificação de terras agricultáveis e a perda de espécies da flora e fauna são problemas ambientais que começaram a ser discutidos entre as décadas de 1970 e 1980.

(2) Por exemplo, o acidente químico em Seveso, Itália (1976); o acidente nuclear em Three Mile Island, Estados Unidos (1979); o vazamento de gases tóxicos em Bhopal, Índia (1984) e o mais grave acidente nuclear da história ocorrido em Chernobyl, Ucrânia (1986), de acordo com HENKES, S. L. As decisões político-jurídicas frente à crise hídrica e aos riscos: lições e contradições da transposição do rio São Francisco. Florianópolis, 2008. 451 f. Tese (Doutorado) - Universidade Federal de Santa Catarina, Centro de Ciências Jurídicas. Programa de Pós-Graduação em Direito. p. 156.

(3) Como a Encefalopatia Espongiforme Bovina popularmente conhecida como a Doença da Vaca Louca que causou uma epidemia animal sem precedentes no Reino Unido, em 1986 e a transmissão do vírus influenza ( $\mathrm{H} 5 \mathrm{~N} 1)$ das aves para mamíferos e seres humanos em casos constatados na Turquia, Romênia, Inglaterra e Alemanha nos anos 1997, 2005 e 2006, segundo HENKES, S. L., op. cit., p.156. 
parâmetro do risco ganhou destaque no meio acadêmico(4). Diante disso, a eficácia das técnicas e das tecnologias passou a ser contestada.

Os riscos engendraram intensas transformações não somente ambientais, mas também sociais, políticas, econômicas, culturais e jurídicas. Então, paulatinamente, novas formas de gerir o risco começaram a ser adotadas.

O Direito, em especial, assumiu papel preponderante na gestão dos riscos; em decorrência, a tendência das normas jurídicas consistiu em se harmonizar ao novo contexto social. Criaram-se novos direitos, garantias e instrumentos $^{(5)}$ e algumas normas existentes foram readequadas.

O presente artigo tem como escopo analisar um dos principais instrumentos jurídicos utilizados na gestão dos riscos: a responsabilidade civil ambiental, no intuito de contribuir para o seu aprimoramento, por meio do debate e da reflexão. A problemática principal do trabalho é avaliar se as normas da responsabilidade civil ambiental no Direito brasileiro são eficazes ou não, no controle e gestão dos riscos.

A realização deste trabalho se justifica em razão da relevância do tema e do desconhecimento dos novos contornos da responsabilidade civil ambiental, bem como de suas peculiaridades pelos profissionais do Direito e pesquisadores em geral, em que pese o incremento das pesquisas nos últimos anos.

\section{METODOLOGIA}

Para a realização deste trabalho, adotou-se o método de pesquisa monográfico e as técnicas de pesquisa bibliográfica e documental por meio da consulta a diversos documentos, obras e artigos nacionais e internacionais com o objetivo de apresentar as diversas interfaces e posições acerca da temática proposta. Ainda citaram-se alguns julgados do Tribunal de Justiça do Estado do Rio Grande do Sul e de Santa Catarina visando a

(4) BECK, U. La sociedad del riesgo global. Madrid: Siglo Veintiuno de España Editores, 1999; Id. La sociedad del riesgo: hacia una nueva modernidad. Barcelona: Paidos, 1986; DOUGLAS, M. La aceptabilidad del riesgo según las ciencias sociales. Barcelona: Paidós Studio, 1996; GIORGI, R. de. Direito, democracia e risco: vínculos com o futuro. Porto Alegre: Sérgio Fabris Editor, 1998; LUHMANN, N. Sociología del riesgo. Cidade do México: Triana Editores, 1998, entre outros autores estudam o risco a partir de diferentes abordagens.

(5) Além do direito à participação em audiências públicas (Resolução do CONAMA n. 09/87) e em conselhos e comitês (Lei n. 9.433/97), hoje o cidadão tem legitimidade para promover ação popular ambiental e anular ou impedir atos lesivos ao ambiente (Lei n. 4.717/65), assim como direito à informação de conteúdo ambiental existente em órgãos públicos (Lei n. 10.650/03) e, principalmente o direito/dever ao meio ambiente ecologicamente equilibrado (CF/88, art. 225). Dentre os instrumentos criados para controlar e gerir o risco destacam-se o licenciamento ambiental e a responsabilização civil frente aos danos futuros e riscos de danos. 
constatar se as decisões tomadas por esses tribunais se coadunam com as normas jurídicas e com os entendimentos doutrinários apresentados. Foram pesquisados julgados a partir de 2003, portanto, a partir da vigência do Novo Código Civil.

\section{A TUTELA JURÍDICA FRENTE AOS RISCOS}

\section{A inserção do risco no Direito: breve contexto histórico}

Embora esteja em evidência desde o lançamento da obra de Ulrich $B e c{ }^{(6)}$, o risco não constitui um tema, nem mesmo um problema novo. O primeiro emprego do termo, afora a sua utilização coloquial, como sinônimo de probabilidade, aventura, perigo, ocorreu no século XIV, quando ele começou a ser usado pelo Direito italiano, na realização dos contratos de seguros marítimos.

Irrompeu com força, todavia, a partir do século XIX, quando então passou a ser objeto de estudos científicos multíplices: sociológicos, econômicos, políticos, filosóficos, mas em especial, jurídicos.

Vale salientar que, a partir da Revolução Industrial (1789), século XVIII, mais exatamente mediante a inserção de novas técnicas e máquinas no processo industrial, começaram a ser percebidas as conexões entre a amplitude dos riscos laborais e as limitações do Direito no campo da responsabilidade civil, em especial, pelos acidentes de trabalho.

Evidenciou-se que o sistema de responsabilização civil fundado na culpa - então exclusivamente adotado - não apresentava respostas adequadas aos problemas da época, visto que os empregados, por exemplo, ficavam sem indenização pelos danos sofridos nos acidentes de trabalho, pois não conseguiam comprovar a culpa do empregador, tampouco falhas nas máquinas; consequentemente, não obtinham o direito à reparação dos danos $^{(7)}$. Em muitos casos, os danos decorriam da inexperiência, diga-se, "culpa" da própria vítima, ou seja, do empregado e não do empregador ou de falhas nas máquinas.

Antes mesmo de o Direito apresentar soluções factíveis para os problemas decorrentes da não indenização dos acidentes de trabalho (riscos laborais), o tema já era objeto de profundas reflexões em outras ciências, por exemplo, Sociologia e Filosofia. Elas, em especial, refletiam sobre as consequências e malefícios da industrialização na vida do proletariado. A obra "O Manifesto Comunista" de Marx e Engels (1848) representa um dos ícones dessa reflexão.

(6) BECK, U. La sociedad del riesgo: hacia una nueva modernidad, cit.

(7) SANSEVERINO, P. de T. Fundamentos da responsabilidade civil. 2008. p. 8. Datilografado. 
Em 1897, surgiu, na França, uma tentativa de resposta, no plano jurídico, para os riscos decorrentes da industrialização, em especial, no ambiente de trabalho. Os juristas Raymond Saleilles e Louis Josserand, em obras autônomas, desenvolveram a Teoria do Risco da Atividade. A diferença entre as mencionadas obras era que a primeira tratava dos acidentes de trabaIho, buscando estabelecer uma nova interpretação da noção de falta, isto é, de culpa (faute), substituindo-a por fato (fait) ${ }^{(8)}$. Desse modo, bastaria que o dano sofrido pela vítima fosse originado de um determinado fato, independentemente da configuração da culpa. A segunda se preocupava com os perigos ensejados por determinados fatores ${ }^{(9)}$.

Embora dissonantes os caminhos, os autores chegaram a uma conclusão semelhante: o empreendedor, ao desenvolver atividade econômica, digase, lucrativa em seu próprio proveito, auferindo lucros e vantagens, deveria suportar o ônus e os encargos dela decorrentes, independente da aferição da culpa (imprudência, negligência e imperícia) e dolo.

A lei trabalhista francesa de 9 de abril de 1898 foi uma das primeiras a introduzir a responsabilidade civil pelo risco da atividade, iniciando a socialização dos prejuízos decorrentes dos riscos no âmbito do trabalho(10).

Esclarece-se que a Teoria do Risco da Atividade não foi bem recebida pela doutrina francesa repercutindo, por isso, negativamente, na internacional. A principal crítica residia no aspecto ético-moral e, acreditavam os seus opositores, que a responsabilidade subjetiva respondia aos anseios da época. A resistência francesa na adoção da Teoria do Risco da Atividade irradiou-se para outros países. A teoria foi adotada muito lentamente na França e, depois, em outras nações.

A mencionada teoria ingressou no Direito brasileiro somente ao longo do século $X X$, portanto, quase um século depois de sua origem. O Código Civil de 1916 ignorou-a completamente. No entanto, ela foi sendo introduzida no ordenamento jurídico brasileiro, lentamente, por meio de leis esparsas: a) Decreto-lei n. 2.681/1912, acerca da responsabilidade pelos danos causados pelas estradas de ferro; b) as leis do seguro obrigatório; c) por intermédio das constituições, onde se destacam: a Constituição Federal de 1946 e a de 1988 que adotaram a Teoria do Risco Administrativo.

Cumpre salientar que a Constituição Federal de 1988, afora a adoção da Teoria do Risco Administrativo, contribuiu sobremaneira para a reorientação das normas jurídicas frente aos riscos, ao instituir, como fundamento da República Democrática do Brasil, a cidadania, a dignidade da pessoa, a valorização do trabalho (art. $1^{\circ}$ ). Atribuiu, como objetivos, a construção de

(8) SANSEVERINO, P. de T., op. cit.

(9) Id. Ibid.

(10) WATEL, P. P. Sociologie du risque. Paris: Armand Colin, 2003. p. 7-10. 
uma sociedade livre, justa e solidária (art.3ำ); positivou o direito à vida, à liberdade, à igualdade, à segurança, à saúde e ao meio ambiente (cf. arts. 5º, 6ำ e 225), como direitos fundamentais.

E ainda, em seu art. 225, parágrafo único, incisos V e VII, preceitua que:

Para assegurar a efetividade desse direito [ao meio ambiente ecologicamente equilibrado], incumbe ao Poder Público:

$V$ - controlar a produção, a comercialização e o emprego de técnicas, métodos e substâncias que comportem risco para a vida, a qualidade de vida, e o meio ambiente;

VII - proteger a fauna e a flora, vedadas, na forma da lei, as práticas que coloquem em risco sua função ecológica, provoquem a extinção de espécies ou submetam os animais a crueldade;

Evidencia-se que as normas infraconstitucionais, sejam especiais ou gerais, devem estar de acordo com o texto constitucional, isto é, seus fundamentos, objetivos, direitos e preceitos.

O Direito Civil brasileiro, a partir do Código Civil de 2002 (CC/2002), apesar de adotar como regra a responsabilidade civil subjetiva — fundada na culpa e no dolo - , emprega a responsabilidade objetiva, fundada no risco da atividade como sistema excepcional de responsabilização. Mas, mesmo esta sendo a exceção, tem sido muito utilizada, porquanto grande parte das atividades desenvolvidas "apresenta risco para os direitos de outrem", caso em que é empregada, consoante o art. 927, parágrafo único do CC/2002.

\section{A responsabilidade civil no Direito Ambiental Brasileiro}

Acerca da responsabilidade civil ambiental, cumpre mencionar que desde a instituição da Política Nacional do Meio Ambiente (Lei n. 6.938/1981), o Direito brasileiro erigiu a responsabilidade objetiva como fundamento da responsabilização civil pelos danos perpetrados ao ambiente. Nesse sentido, dispõe o seu art. 14, § 1: "Sem obstar a aplicação das penalidades prevista neste artigo, é o poluidor obrigado independentemente da existência de culpa, a indenizar ou reparar os danos causados ao meio ambiente e a terceiros afetados por sua atividade [...]."

O Código Civil de 2002 (Lei n. 10.406/2002), em sintonia com os novos desafios, afora a responsabilidade civil subjetiva (arts. 186 e 187), portanto, baseada no elemento subjetivo determinante da conduta, isto é, culpa (imprudência, negligência e imperícia) e dolo, como regra em nosso ordenamento, estabeleceu a responsabilidade objetiva como sistema suplementar, para os casos especificados em lei ou quando a atividade desenvolvida pelo autor do dano implicar, por sua natureza, risco para os 
direitos de outrem, como, por exemplo, o direito à saúde, à vida, à segurança entre outros, consoante o art. 927, parágrafo único.

Destarte, ao se tratar de responsabilidade civil por agressões ao meio ambiente e quaisquer outras que impliquem riscos, por exemplo, à saúde pública, à coletividade, aplicar-se-á, irrefutavelmente, a responsabilidade objetiva prevista em lei, no caso ambiental, a Lei n. 6.938/1981 e nos demais casos, porque decorre dos riscos da atividade.

O conceito de risco, empregado no estatuto civil, ainda que não contenha o conteúdo sociológico tal como utilizado por Beck e demais autores, representa a probabilidade/possibilidade, contingência ${ }^{(11)}$ de um evento/atividade causar danos. Desse modo, demonstra a harmonia do diploma pátrio com o contexto contemporâneo global.

Embora não haja dúvidas acerca da aplicação da teoria objetiva na responsabilização civil por danos ambientais, há dissenso no tocante à teoria objetiva a ser empregada: Teoria do Risco Proveito, também definida como Integral ou a Teoria do Risco Criado. Ambas são teorias objetivas; entretanto, a adoção de uma ou de outra apresenta repercussões distintas, principalmente no que tange ao emprego ou não de excludentes de responsabilização e na determinação do nexo de causalidade (alargado ou restrito).

Importa, no entanto, salientar que, independentemente da teoria empregada, deve haver a reparação integral do dano, ainda que se trate de conduta lícita, indiferentemente, portanto, de estar ou não de acordo com a licença ambiental.

\subsection{As teorias aplicadas à responsabilidade civil fundada no risco}

A responsabilidade civil no Direito brasileiro, em específico quando aplicada às agressões ao meio ambiente, tem adquirido novos contornos, condizentes com a realidade induzida pela sociedade de risco; por esta razão, torna-se fundamental o conhecimento das mencionadas teorias, porque a aplicação de uma ou de outra conduz a resultados diversos: maior ou menor proteção ambiental.

A Teoria do Risco Proveito ou Integral estabelece que o responsável pelo dano tem o dever de repará-lo, ou cessar e impedir que circunstâncias adversas gerem danos futuros ou coloquem em risco a coletividade, pois ele será responsabilizado por todo e qualquer ato; ou seja, independentemente da ocorrência de danos efetivos, basta a possibilidade de ocorrência de riscos à coletividade.

(11) Termo usado por BRÜSEKE, F. J. A técnica e os riscos da modernidade. Florianópolis: Ed. da UFSC, 2001. 
Essa teoria não admite nenhuma excludente de responsabilidade, como, por exemplo, caso fortuito, força maior, ação da vítima ou de terceiro. Ela tem como embasamento o fato de que aquele que aufere proveitos/lucros com a atividade deve arcar com os prejuízos dela decorrentes.

Outra característica dessa teoria é não diferenciar as causas principais das secundárias, intrínsecas ou não, à atividade; todas são consideradas condições do evento lesivo e, por si só, aptas a gerar a responsabilização. Trata-se da aplicação do princípio poluidor-pagador o qual visa internalizar as externalidades ambientais negativas no processo produtivo pelo responsável, evitando-se a socialização dos custos e dos riscos dele decorrentes.

Consoante Steigleder ${ }^{(12)}$, a teoria mencionada estabelece que "todo e qualquer risco conexo ao empreendimento deverá ser integralmente internalizado no processo produtivo, devendo o responsável reparar quaisquer danos que tenham conexão com sua atividade".

A Teoria do Risco Criado(13) estabelece que, na verificação da responsabilidade, dentre todos os possíveis fatores de risco, somente devem ser considerados aqueles que, por apresentarem periculosidade, são efetivamente aptos a gerar as situações lesivas. Deste modo, admite a aplicação de excludentes de responsabilidade (culpa exclusiva da vítima, fatos de terceiros, caso fortuito e força maior), pois, para tal teoria, tais fatos têm o condão de romper o curso do nexo causal.

Importa salientar que nem todos os atos praticados por terceiros têm o condão de afastar a aplicação do nexo causal, logo, a responsabilidade civil. Assim como os pais e tutores respondem objetivamente pelos atos dos filhos e pupilos, o empregador responderá pelos atos praticados por seus empregados e subalternos no exercício do trabalho ou em razão dele, consoante os arts. 932 e 933 do Código Civil/2002. Dessa forma, o diretor de uma fábrica de produtos tóxicos responderá objetivamente, ou seja, independentemente da verificação de sua negligência ou imprudência, pelos danos decorrentes dos atos dos seus empregados que, por exemplo, lançarem carga tóxica sem tratamento nos cursos d'água ou no ar.

Cabe destacar a existência da Teoria dos Riscos do Desenvolvimento, prevista na Convenção de Lugano (art. $35-1$ ) e aplicada no Direito Civil francês (Código Civil Francês, art. 1386-1, 4ํ), sendo prevista no Direito brasileiro (Código de Defesa do Consumidor, art. 12, § 1ำ, inciso III). Segundo esta teoria(14), exime-se, ou não, a responsabilidade civil pelos danos causados, no caso ao meio ambiente, do responsável que provar que, à época da

(12) STEIGLEDER, A. M. Responsabilidade civil ambiental: as dimensões do dano ambiental no direito brasileiro. Porto Alegre: Livr. do Advogado, 2004. p. 198.

(13) Id. Ibid.

(14) OUDOT, P. Le risque de développement. contribution au mantien du droit à reparation. Dijon: Éditions Universitaires de Dijon, 2005. p. 27 e ss. não traduzido no original. 
sua circulação, eram desconhecidos os defeitos e perigos do produto/serviço ou eram de impossível previsão científica e técnica.

Trata-se, na verdade, da existência de um caso fortuito que pode ser analisado a partir das teorias mencionadas. Assim, não se constitui teoria independente: a) se empregada a Teoria do Risco Proveito, não se admitiria a excludente e o responsável pela circulação do produto responderia pelos danos causados, ainda que à época não fossem conhecidos; b) empregando-se a Teoria do Risco Criado, haveria a exclusão da responsabilidade em razão do caso fortuito.

\subsection{Os pressupostos da responsabilidade civil fundada no risco}

Os quatro pressupostos da responsabilidade civil são: conduta, resultado, nexo de imputação e nexo causal. No entanto, tratando-se da responsabilização de condutas decorrentes do exercício de atividades que impõem riscos à coletividade, ou de lesões aos direitos ou interesses difusos e coletivos, como o meio ambiente, as relações de consumo e a saúde pública, a análise desses pressupostos têm significativas alterações, decorrentes da especificidade do objeto tutelado.

A responsabilidade civil dos interesses e direitos de cunho difuso/coletivo rompe com a interpretação conservadora dos pressupostos da responsabilidade civil aplicada às lesões de direitos ou interesses individuais, ou seja, às relações jurídicas privadas.

\section{2.a. Conduta}

Considera-se responsável pela conduta, tanto o agente que direta ou indiretamente agiu, pois segundo a Lei 6.938/1981 (art. 3o, IV), poluidor é "a pessoa física ou jurídica, de direito público ou privado, responsável, direta ou indiretamente, por atividade causadora de degradação ambiental". Convém destacar que, em se tratando de responsabilidade objetiva, na análise da conduta, não se verifica o elemento subjetivo desta (dolo/culpa), nem mesmo se esta conduta é lícita ou ilícita, mas, sim, o seu conteúdo material.

Versando sobre responsabilidade civil por danos ambientais, aplicase a responsabilidade solidária. Desse modo, todos os agentes, somente um, ou alguns, responderão. Aquele que suportar sozinho a responsabilidade poderá se voltar contra os demais, via ação regressiva ${ }^{(15)}$.

(15) LEITE, J. R. M. Dano ambiental: do individual ao coletivo extrapatrimonial. 2. ed. São Paulo: Ed. Revista dos Tribunais, 2003. p. 181. 
Por sua vez, a adoção da responsabilidade solidária tem como escopo evitar a ausência de responsabilização, quando o resultado decorre direta ou indiretamente de múltiplas causas ou praticados por vários agentes. Tal fato revela-se comum frente ao contexto hodierno, haja vista a acumulação dos agentes nocivos no tempo (bioacumulação e biomagnificação). A solidariedade tem como alicerce a concepção do dano ambiental como fato único e indivisível(16).

De acordo com a Constituição Federal de 1988 (art. 23, VI), incumbe ao Estado: "proteger o meio ambiente e combater a poluição em qualquer de suas formas." No mesmo sentido, o art. 225 da CF/88 prescreve: "Todos têm direito ao meio ambiente ecologicamente equilibrado, bem de uso comum do povo e essencial à sadia qualidade de vida, impondo-se ao Poder Público e à coletividade o dever de defendê-lo e preservá-lo para as presentes e futuras gerações."

Por conseguinte, o Estado (Estados, Distrito Federal, Municípios e a União) além de ser responsabilizado pelos danos cometidos por seus agentes (conduta comissiva), também poderá ser responsabilizado pelos danos ambientais cometidos por outrem, como, por exemplo, cidadãos e empresas, em decorrência da sua conduta omissiva, ao não fiscalizar efetivamente as atividades poluidoras, deixando que danos ao ambiente sejam gerados.

Do mesmo modo, a responsabilidade do Estado é verificada também quando: a) não prestar os serviços públicos indispensáveis, como o acesso à água, ao saneamento básico, à saúde, entre outros, em virtude da sua omissão; b) prestar os serviços em desacordo com o prescrito constitucionalmente, ou seja, de forma precária; c) provocar danos ou impuser riscos à coletividade.

Nesses casos, a responsabilidade do Estado é patrimonial extracontratual, isto é, ele tem a obrigação de reparar economicamente os danos lesivos à esfera juridicamente garantida de outrem e que lhe sejam imputáveis, em decorrência de comportamentos unilaterais, lícitos ou ilícitos, comissivos ou omissivos, materiais ou jurídicos, consoante Mello(17).

Ainda, segundo o autor ${ }^{(18)}$, a responsabilidade do Estado tem princípios próprios compatíveis com a peculiaridade de sua posição jurídica; sem isso, o acobertamento dos particulares contra os riscos da ação pública seria irrisório e insuficiente para o resguardo dos interesses e bens jurídicos da coletividade. Cabe também salientar que, em muitos casos, os administrados não têm como evadir ou sequer minimizar os riscos ou os danos provenientes da conduta estatal.

(16) STEIGLEDER, A. M., op. cit., p. 208.

(17) MELLO, C. A. B. de. Curso de direito administrativo. 14. ed. São Paulo: Malheiros Ed., 2002. p. 835.

(18) lb., lbid. p. 838 e ss. 
Ademais, quanto à responsabilidade do Estado, o texto constitucional (art. 37, $\S 6^{\circ}$ ) dispõe que as pessoas jurídicas de direito público e privado prestadoras de serviços públicos responderão pelos danos que seus agentes, nessa qualidade, causarem a terceiros. Assegura, além disso, o direito de regresso contra o responsável nos casos de dolo ou culpa.

Não obstante, a aplicação uniforme da responsabilização objetiva do Estado é contestada. Leite ${ }^{(19)}$ destaca que todas as atividades de risco ao meio ambiente estão sob controle do Estado e, em tese, o mesmo responderia solidariamente pelo dano ambiental provocado por terceiros, ante o dever constitucional de proteger o meio ambiente. Para $\mathrm{Me} \mathrm{o}^{(20)}$, o problema crucial reside em saber se basta a mera objetividade de uma conduta estatal lesiva a terceiro ou se é necessário que o comportamento danoso seja viciado por culpa, por exemplo, falta de serviço ou dolo na conduta.

Mello(21) leciona que a responsabilidade do Estado se difere conforme as seguintes situações: a) se o próprio comportamento do Estado gerar o dano (conduta comissiva); b) se não há uma atuação do Estado na produção do dano, mas o dano é produzido em virtude da sua omissão e ele deveria tê-lo evitado (falta de serviço, serviço não funcionou ou funcionou tardiamente); c) não foi a atuação do Estado que produziu o dano, mas é por atividade dele que se cria a situação geradora de danos ou que se expõe pessoas ao risco. Segundo o autor, na primeira (a) e na terceira (c) hipóteses, a responsabilidade do Estado é objetiva, enquanto na segunda (b), é subjetiva.

Por sua vez, as pessoas jurídicas de direito privado também serão responsabilizadas objetivamente, quando forem responsáveis direta ou indiretamente por atividade causadora de degradação. Nesse sentido, as empresas respondem não somente pelas condutas próprias (direta), por exemplo, a dos funcionários, gerentes, administradores, mas também por aquelas desenvolvidas por seus colaboradores, pessoas que exerçam atividades com vínculo indireto ou até mesmo sem vínculo formal estabelecido, mas aufiram lucros com a conduta de outrem.

Nesse caso, pode ser citada a responsabilização solidária das cooperativas $^{(22)}$ que lucram com a atividade do cooperado, mantendo vínculo indireto, pois fornecem insumos, orientação técnica, entre outros. Elas respondem conjuntamente com os cooperados pelos danos ambientais decorrentes da atividade desenvolvida.

(19) LEITE, J. R. M., op. cit., p. 197.

(20) MELLO, C. A. B. de. op. cit., p. 851-861.

(21) Id. Ibid., p. 833 e ss.

(22) Neste sentido, consultar: BRASIL. Tribunal de Justiça do Estado de Santa Catarina. Apelação Cível n. 2003.019381-2. Apelante: Tractebel Energia S.A. Apelado: Sebastião Antunes Maciel. Relator: Maria do Rocio Luz Santa Ritta. Florianópolis, 30 ago. 2005. Disponível em: <http:// www.tjsc.gov.br>. Acesso em: ago. 2007. 
Não se pode olvidar que, além da responsabilização na esfera cível, as pessoas jurídicas, assim como as físicas, podem responder pelas agressões cometidas ao meio ambiente, no campo administrativo e penal (art. 225, § 3ำ da CF/88).

\section{2.b. Resultado}

Embora, para muitos autores, somente seja considerado como resultado apto a gerar a responsabilidade civil o dano efetivo - , portanto, concreto e materializado - , é imperativo afirmar que o resultado também pode ser o dano futuro (certo, mas ainda não perpetrado) ou risco de dano (provável, contudo, destituído de certeza, mas não hipotético).

Em decorrência da aplicação das normas ambientais à luz dos princípios ambientais, dentre os quais se destacam: princípio do poluidor-usuário-pagador, da prevenção, da precaução, da responsabilidade, entre outros, e dos fundamentos, objetivos, direitos e preceitos constitucionais visando, sobretudo, a dar efetividade aos direitos positivados (saúde, vida, segurança, meio ambiente etc.) importa reavaliar as antigas lições, em específico aquelas sobre a responsabilidade civil decorrente da violação de direitos ou interesses difusos e coletivos. É indubitável que, hodiernamente, a tutela jurídica tem como objetivo primordial evitar e prevenir o dano e as lesões, assim como a geração de riscos aos mais diversos interesses e direitos.

No contexto atual, indispensável será levar em consideração que o resultado de uma conduta (dano futuro, risco de dano) pode configurar algo distinto do dano (dano efetivo). Porém, doutrinadores ${ }^{(23)}$ e a jurisprudência ${ }^{(24)}$ ainda lecionam que o dano é pressuposto para a responsabilização.

$\mathrm{Na}$ verdade, o objetivo maior da norma jurídica é prevenir a ocorrência de situações lesivas, impondo-se a responsabilização frente aos riscos e danos futuros. Assim, a aplicação das regras positivadas e, em alguns casos, a readequação delas à luz dos princípios ambientais e do texto constitucional motivou que as regras da responsabilização civil, em face dos interesses e

(23) DINIZ, M. H. Curso de direito civil brasileiro. 19. ed. São Paulo: Saraiva. 2005. v. 7, p. 43 e ss. GAGLIANO, P. S.; PAMPLONA FILHO, R. Novo curso de direito civil: responsabilidade civil. São Paulo: Saraiva, 2003. p. 39 e ss.

(24) A título exemplificativo, citam-se os seguintes acórdãos: BRASIL. Tribunal de Justiça do Estado do Rio Grande do Sul. Agravo de Instrumento n. 70023122872. Agravante: Rodonaves Transportes e Encomendas. Agravado: Ministério Público. Relator: Arno Werlang. Porto Alegre, 06 ago. 2008. Disponível em: <http://www.tjrs.gov.br>. Acesso em: dez. 2008; BRASIL. Tribunal de Justiça do Estado do Rio Grande do Sul. Agravo de Instrumento n. 70017697715. Agravante: Ministério Público. Agravado: Claro S.A., Tim Celular S.A., Brasil Telecom S.A. e Vivo. Relator: João Armando Bezerra Campos. Porto Alegre, 07 mar. 2007. Disponível em: <http://www.tjrs.gov.br>. Acesso em: dez. 2008. 
direitos difusos e coletivos, sofressem significativas alterações. Hoje, vislumbra-se com nitidez a sua (tentativa de) conformação com a realidade contemporânea de incertezas, riscos e catástrofes globais e intergeracionais. Cumpre ratificar que o Direito Ambiental reconheceu a incerteza científica frente ao contexto contemporâneo, ao adotar o princípio da precaução.

Enfatiza-se que a responsabilidade civil aplicada aos direitos e interesses difusos e coletivos, tornou-se um importante instrumento de gestão e controle dos riscos, em decorrência da imposição de medidas acautelatórias.

Inquestionavelmente, a maior inovação da responsabilidade civil brasileira, no que tange à tutela dos interesses e direitos difusos, decorre da possibilidade de prevenir a ocorrência de danos e impedir a geração de riscos à coletividade mediante a responsabilização pelo cometimento de dano futuro e risco de dano. A doutrina ${ }^{(25)}$ e a jurisprudência ${ }^{(26)}$ — esta ainda muito incipiente - defendem esse entendimento.

O dano futuro e o risco de dano são figuras jurídicas distintas. Aquele diz respeito à ocorrência certa (não hipotética e não provável) de um dano que se materializará em tempo futuro, caso não sejam tomadas medidas para impedi-lo. Também se constituem dano futuro as consequências futuras de um dano já consumado. Como exemplo deste tipo de evento, pode-se mencionar aqueles decorrentes da infiltração no solo ou no lençol freático de poluentes (materiais químicos, físicos, orgânicos), que se dará cedo ou tarde, em decorrência da não impermeabilização do solo com materiais altamente resistentes, tais como as geomembranas em polietileno de alta densidade (PEAD), por exemplo, nas lagoas de tratamento de efluentes líquidos, aterros sanitários de lixo urbano, aterros de resíduos sólidos industriais, esterqueiras, entre outros.

Nesses casos, o dano é certo quanto a sua materialização, pois está provado que o esterco e os resíduos sólidos e efluentes líquidos das atividades

(25) Consultar: LEITE, J. R. M., op. cit., p. 126; STEIGLEDER, A. M., op. cit., p. 181; CARVALHO, D. W. de. Dano ambiental futuro: a responsabilização civil pelo risco ambiental. Revista de Direito Ambiental, São Paulo, ano 12, n. 45, p. 62-91, jan./mar. 2007; Id. Novas tecnologias e os riscos ambientais. In: LEITE, José Rubens Morato; FAGÚNDEZ, Paulo Roney Ávila. Biossegurança e novas tecnologias na sociedade de risco: aspectos jurídicos, técnicos e sociais. Florianópolis: Conceito Editorial, 2007. p. 71-90.7b.

(26) Nesse sentido, consultar: BRASIL. Tribunal de Justiça do Estado de Santa Catarina. Agravo de Instrumento n. 2007.003626-4. Agravante: Ministério Público. Agravado: Emocol Participações Imobiliárias Ltda. Relator: Des. Vanderlei Romer. Florianópolis, 10 maio 2007. Disponível em: <http:/ /www.tjsc.gov.br>. Acesso em: ago. 2007; BRASIL. Tribunal de Justiça do Estado de Santa Catarina. Agravo de Instrumento n. 2005.021403-7. Agravante: RM Participações e Incorporações de Imóveis Ltda. Agravado: Ministério Público. Relator: Des. Cid Goulart. Florianópolis, 25 abr. 2006. Disponível em: <http://www.tjsc.gov.br>. Acesso em: ago. 2007; BRASIL. Tribunal de Justiça do Estado do Rio Grande do Sul. Agravo de Instrumento n. 70012938981. Agravante: Celular CRT S.A. Apelado: Ministério Público. Relator: Des. Paulo de Tarso Vieira Sanseverino. Porto Alegre, 16 mar. 2006. Disponível em: <http://www.tjrs.gov.br>, entre outros. 
mencionadas contêm material altamente poluidor e, muitas vezes, com ação persistente no tempo. Se não forem tomadas cautelas adequadas, haverá infiltração no solo ou no lençol freático, causando deteriorações no decorrer do tempo; portanto, futuras.

Se já houver dano ambiental — degradação do solo ou poluição das águas do lençol freático - a não impermeabilização dos reservatórios pode agravar os prejuízos já consumados, gerando danos futuros, por meio da bioacumulação de material tóxico e dos efeitos da reação em cadeia.

Mirra $^{(27)}$ leciona acerca do dano futuro:

$O$ dano deve ser certo quanto à sua existência. A certeza relaciona-se não somente quanto ao caráter atual do dano, vale dizer, aquele já iniciado ou consumado, mas também do dano futuro se ele aparece como inevitável, ainda que a sua extensão seja momentaneamente indeterminada. Ao dano certo opõe-se o eventual, o qual não dá direito à reparação, em virtude de ser um prejuízo hipotético.

O risco de dano se fundamenta na elevada probabilidade (diversa de hipotética eventualidade e de ocorrência certa) do cometimento de riscos à coletividade e ao meio ambiente, em decorrência do exercício de uma determinada conduta ou atividade, por exemplo, na utilização de novas técnicas e tecnologias, como a transgenia, estações de rádio-base, entre outras.

Pode-se afirmar que a adoção do princípio da prevenção impede a ocorrência do dano futuro, visto que baseado em conhecimento do resultado (certo); já a aplicação do princípio da precaução se aproxima da obstrução do risco, uma vez que não se tem certeza absoluta do resultado. Na verdade, as controvérsias e dúvidas científicas e técnicas quanto à existência de riscos não devem obstaculizar a adoção de medidas, visando proteger a coletividade, as presentes e futuras gerações.

Dentre os doutrinadores que defendem a responsabilidade civil frente ao risco de dano e dano futuro, destacam-se Leite e Steigleder. Para Leite ${ }^{(28)}$, "[...] a simples atividade geradora de riscos potenciais e não de danos concretos, podem suscitar a responsabilização do agente e obrigá-lo a cessar a atividade nociva, obviamente com fundamento nas provas e na utilização do princípio da precaução do Direito Ambiental". E ainda(29): "[...] a responsabilidade objetiva tem como base a socialização do lucro ou do dano, considerando que aquele que obtém lucro e causa dano com uma atividade, deve responder pelo risco ou pela desvantagem dela resultante."

Steigleder ${ }^{(30)}$ afirma que o sistema pode se abrir para hipóteses de responsabilização sem danos consumados, nas situações em que o risco

(27) MIRRA, Á. L. V. Ação civil pública e a reparação do dano ao meio ambiente. 2. ed. São Paulo: Juarez de Oliveira, 2002. p. 65.

(28) LEITE, J. R. M., op. cit., p. 124-125.

(29) Ib. Ibid., p. 126.

(30) STEIGLEDER, A. M., op. cit., p. 181. 
gerado por atividades intrinsecamente perigosas demanda intervenção, para suprimir o fator de risco, que deverá ser internalizado no processo produtivo.

Em síntese, cumpre destacar que o dano ambiental pode vitimar a coletividade (presentes ou futuras gerações) e também pessoas determinadas, lesando-os patrimonial ou extrapatrimonialmente ${ }^{(31)}$. A reparação desses danos pode ser cumulada, consoante a Súmula n. 37 do Superior Tribunal de Justiça, que afirma que podem ser acionadas judicialmente pelos danos perpetrados ao meio ambiente, tanto a pessoa física quanto a jurídica.

Quando considerado o meio ambiente como um todo imaterial e indivisível, portanto, o bem maior ambiental, as lesões (patrimoniais e extrapatrimoniais) afetam os interesses difusos e coletivos. Sua tutela é realizada mediante ações coletivas em defesa das presentes e futuras gerações.

Além disso, determinadas agressões podem afetar o meio ambiente em escalas menores e, de modo reflexo, atingir e lesar interesses privados. Surge, então, o dano ambiental individual, causado por intermédio do meio ambiente ${ }^{(32)}$, como, por exemplo, o caso jurisprudencial a seguir mencionado (item 2.2.e.) que, ao atingir o rio Uruguai, lesou também uma pessoa. Ao atingir os recursos naturais em si, e não ao meio ambiente como um todo, são gerados prejuízos (danos patrimoniais e extrapatrimoniais) a determinadas pessoas. Sua reparação deverá ser pleiteada por meios processuais de tutela individual: ação de indenização.

\section{2.c. Nexo de Imputação}

O Código Civil de 2002, em seus arts. 186 e 187, institui a responsabilidade subjetiva como regra. Por conseguinte, em nosso ordenamento, o nexo de imputação subjetivo é a regra; mas quando a atividade gerar riscos para os direitos de outrem, ou quando a lei dispuser que deva ser aplicada a responsabilidade objetiva, o nexo de imputação é o objetivo. Neste caso, não se busca a determinação de culpa ou dolo, tampouco se a conduta é lícita ou ilícita.

\section{2.d. Nexo causal}

Primeiramente, convém definir que o nexo causal "é o vínculo estabelecido entre a conduta do agente e o resultado por ela gerado"(33). Ao se tratar de responsabilidade civil, constata-se a prevalência de duas teorias.

(31) Sobre o tema, consultar LEITE, J. R. M., op. cit.

(32) Ibidem, p. 138 e ss.

(33) NUCCI, G. de S. Manual de direito penal. São Paulo: Ed. Revista dos Tribunais, 2007. p. 197. 
Adotando-se a Teoria do Risco Integral, empregar-se-á a Teoria da Equivalência das Condições, para aferição do liame causal e, assim, basta que o resultado esteja vinculado, direta ou indiretamente, à existência do fator de risco/dano o qual é reputado causa do dano (resultado) ${ }^{(34)}$.

Essa teoria, segundo Gagliano e Pamplona Filho ${ }^{(35)}$, foi elaborada pelo jurista alemão von Buri, na segunda metade do século XIX, e tem como característica principal não diferenciar os antecedentes do resultado danoso, de forma que tudo aquilo que concorra para evento será considerado causa. Ou seja, "a causa da causa é causa do que foi causado"(36).

Acolhendo-se a Teoria do Risco Criado, emprega-se a Teoria da Causalidade Adequada, ou seja, dentre as diversas causas que podem ter gerado o dano, busca-se aquela que, numa perspectiva de normalidade e adequação social, apresente sérias probabilidades de ter gerado o dano ou risco $^{(37)}$.

Essa teoria foi criada pelo filósofo alemão von Kries e, segundo sua acepção, não se pode considerar como causa toda e qualquer condição que haja contribuído para a efetivação do resultado, mas somente aquela que, segundo um juízo de probabilidade, possa ser considerada o antecedente abstratamente idôneo à produção do efeito danoso(38).

Aludindo-se à verificação do nexo causal, no contexto contemporâneo, conforme Noronha ${ }^{(39)}$, "estamos entrando num segundo momento em que, se verifica haver hipóteses especiais, em que se prescinde também do nexo de causalidade, para se exigir unicamente que o dano acontecido possa ser considerado risco próprio da atividade em causa". Seu entendimento se aproxima do fundamento da Teoria da Equivalência das Condições, pois, para esta teoria, prescinde-se da prova efetiva do nexo - que o dano decorra efetivamente da conduta - para um juízo de probabilidade, sendo suficiente que o risco imposto pela normal conduta possa, em tese, gerar o resultado.

\section{2.e. Dissenso jurisprudencial}

É válido ressaltar que os entendimentos jurisprudenciais acerca da aplicação da responsabilidade civil ambiental não são uniformes. Como incumbe ao operador do direito escolher a teoria consoante seu convencimento, ambas (Teoria do Risco Integral e do Risco Criado) recebem adeptos.

(34) STEIGLEDER, A. M., op. cit., p. 202.

(35) GAGLIANO, P. S.; PAMPLONA FILHO, R., op. cit., p. 96-97.

(36) $\mathrm{NUCCI}, \mathrm{G}$. de S., op. cit., p. 198.

(37) STEIGLEDER, A. M., op. cit., p. 202.

(38) GAGLIANO, P. S.; PAMPLONA FILHO, R., op. cit., p. 99.

(39) NORONHA, F. Desenvolvimentos contemporâneos da responsabilidade civil. Revista dos Tribunais, São Paulo, v. 761, p. 37-38, 1999. 
Cumpre reiterar que a aplicação de uma ou outra teoria causa inúmeros reflexos à proteção ambiental. Aderindo-se à Teoria do Risco Proveito, tem-se a verificação da responsabilidade do autor, mesmo que se prove, em tese, que a atividade ou conduta poderia gerar o dano ou risco de dano; não é necessária a verificação cabal de que a atividade/conduta os gerou; negase a aplicação das excludentes. Assim, coíbe-se a prática de condutas lesivas, ao se impor adstreintes.

Ao ser adotada a Teoria do Risco Criado, exige-se a prova que determinada conduta resultou efetivamente em risco de dano ou dano e, portanto, é mais fácil haver isenção de responsabilidade.

No julgamento da Apelação Cível n. 2003.019122-4(40), no dia 28.05.2004, percebe-se, com nitidez, a divergência dos desembargadores do Tribunal de Justiça do Estado de Santa Catarina (TJSC). Tratava-se do julgamento do recurso interposto contra a decisão da ação de indenização/ responsabilidade civil proposta na Comarca de Chapecó (SC), por Sebastião Antunes Maciel contra Tractebel Energia S.A.

A ação de indenização foi proposta com o intuito de reparação de dano ambiental individual, qual seja, a impossibilidade do seu exercício profissional (pesca), haja vista a mortandade e escassez de peixes, atribuídas à atividade da empresa, ou melhor, ao fechamento das comportas no rio Uruguai para a geração de energia elétrica.

A decisão do juízo a quo condenou a empresa ao pagamento de um salário mínimo mensal ao autor da demanda, pelo período de três anos, pelos danos causados (impossibilidade do exercício profissional). Em recurso ao $2^{\circ}$ grau de jurisdição, a sentença foi reformada e a empresa não foi condenada ao pagamento de indenização pelos danos cometidos.

A decisão majoritária entende não haver prova do nexo causal, embora reconheça a existência de danos decorrentes da instalação da referida usina ao mencionar: "a qual [Tractebel S.A.] neutralizou, na medida do possível e na lógica do razoável, os danos afeitos a sua atividade [...]." Em voto dissidente o Desembargador José Volpato de Souza(41) afirma que, dos autos, pode ser extraída a responsabilidade da empresa, tendo em vista a comprovação do nexo causal entre sua atividade e o resultado/dano.

Todavia, de acordo com o entendimento majoritário do acórdão, a escassez de peixes é gradativa e causada por fatores, como a turbidez provocada pela erosão laminar em terras cultivadas; o aumento de efluentes nocivos

(40) BRASIL. Tribunal de Justiça do Estado de Santa Catarina. Agravo de Instrumento n. 2003.019122-4. Apelantes e Apelados: Tractebel Energia S.A. e Ademar Cardoso dos Santos. Relator: Des. Marcus Túlio Sartorato. Florianópolis, 28 maio 2004. Disponível em: <http://www.tjsc.gov.br>. Acesso em: ago. 2007.

(41) Id. Ibid. 
provenientes das indústrias de processamento de celulose; a criação de suínos às margens dos rios com lançamentos de dejetos e a pesca obscura na época da piracema. Esses fatos (fato de terceiros), de acordo com a Teoria do Risco Criado têm o condão de excluir a responsabilidade da empresa, já que rompem o liame causal. A empresa não foi responsabilizada, sendo reformada a sentença de $1^{\circ}$ grau, por maioria dos votos.

\section{CONSIDERAÇÕES FINAIS}

Na sociedade definida como de risco, a responsabilidade civil ambiental tornou-se uma das principais ferramentas para a gestão do risco. A responsabilidade civil ambiental no Direito brasileiro é objetiva; portanto, irrelevante a verificação do elemento subjetivo da conduta (culpa/dolo) e até mesmo se a conduta é lícita ou ilícita.

As teorias objetivas mais aplicadas são Teoria do Risco Integral e do Risco Criado; mas independentemente da teoria aplicada, os pressupostos da responsabilidade civil adquiriram novos contornos, ainda que a repercussão factual do emprego de um ou outra seja diversa.

O resultado de uma conduta deve ser compreendido como dano futuro, risco de dano ou dano efetivo e não somente este. O primeiro funda-se na certeza de ocorrência, em momento futuro, de um dano, se não forem obstaculizadas as causas, ou ainda, as consequências futuras de danos consumados e decorre da aplicação do princípio da prevenção. Os riscos de danos não têm alicerce na certeza, mas na elevada probabilidade, desde que não hipotética e provêm do emprego do princípio da precaução e do poluidor-usuário-pagador. A sua verificação fundamenta-se na dúvida, isto é, na incerteza técnica e científica. Contudo, em decorrência da gravidade e letalidade de alguns riscos, deve-se agir prontamente para proteger a coletividade. $\mathrm{O}$ dano efetivo é o dano consumado, materializado.

Importa, por derradeiro, enfatizar que o objetivo principal da responsabilidade civil consiste em proteger as presentes e futuras gerações das ações nocivas e da potencialização delas no tempo e no espaço. Acredita-se que a responsabilidade civil ambiental no Direito brasileiro está apta a proteger a coletividade dos riscos, desde que empregada a Teoria do Risco Integral, por ser a mais rigorosa.

\section{REFERÊNCIAS BIBLIOGRÁFICAS}

BECK, U. La sociedad del riesgo global. Madrid: Siglo Veintiuno de España Editores, 1999. 
La sociedad del riesgo: hacia una nueva modernidad. Barcelona: Paidos, 1986.

BRASIL. Tribunal de Justiça do Estado do Rio Grande do Sul. Agravo de Instrumento n. 70023122872. Agravante: Rodonaves Transportes e Encomendas Ltda. Agravado: Ministério Público. Relator: Des. Arno Werlang. Porto Alegre, 06 ago. 2008. Disponível em: <http://www.tjrs.gov.br>. Acesso em: out. 2008.

Tribunal de Justiça do Estado do Rio Grande do Sul. Agravo de Instrumento n. 70017697715. Agravante: Ministério Público. Agravado: Claro Digital e outros. Relator: Des. João Armando Bezerra Campos. Porto Alegre, 07 mar. 2007. Disponível em: <http://www.tjrs.gov.br>. Acesso em: out. 2008.

Tribunal de Justiça do Estado de Santa Catarina. Agravo de Instrumento n. 2005.021403-7. Agravante: RM Participações e Incorporações de Imóveis Ltda. Agravado: Representante do Ministério Público Estadual. Relator: Des. Cid Goulart. Florianópolis, 25 abr. 2006. Disponível em: <http:// www.tjsc.gov.br>. Acesso em: ago. 2007.

Tribunal de Justiça do Estado do Rio Grande do Sul. Agravo de Instrumento n.70012938981. Agravante: Ministério Público Estadual. Agravado: CRT S.A. Relator: Des. Paulo de Tarso Sanseverino. Porto Alegre, 26 mar.2006. Disponível em: <http://www.tjrs.gov.br>. Acesso em: set. 2008.

Tribunal de Justiça do Estado de Santa Catarina. Agravo de Instrumento n. 2007.003626-4. Agravante: Ministério Público. Agravado: Emocol Participações Imobiliárias Ltda. Relator: Des. Vanderlei Romer. Florianópolis, 10 mai. 2007. Disponível em: <http://www.tjsc.gov.br>. Acesso em: ago. 2007.

Tribunal de Justiça do Estado de Santa Catarina. Apelação Cível n. 2003.019381-2. Apelante: Tractebel Energia S.A. Apelado: Sebastião Antunes Maciel. Relator: Maria do Rocio Luz Santa Ritta. Florianópolis, 30 ago. 2005. Disponível em: <http://www.tjsc.gov.br>. Acesso em: ago. 2007.

Tribunal de Justiça do Estado de Santa Catarina. Agravo de Instrumento n. 2003.019122-4. Apelantes e Apelados: Tractebel Energia S.A. e Ademar Cardoso dos Santos. Relator: Des. Marcus Túlio Sartorato. Florianópolis, 28 maio 2004. Disponível em: <http://www.tjsc.gov.br>. Acesso em: ago. 2007.

BRÜSEKE, F. J. A técnica e os riscos da modernidade. Florianópolis: Ed. da UFSC, 2001.

CARVALHO, D. W. de. Dano ambiental futuro: a responsabilização civil pelo risco ambiental. Revista de Direito Ambiental, São Paulo, ano 12, n. 45, p. 62-91, jan./mar. 2007. 
Novas tecnologias e os riscos ambientais. In: LEITE, José Rubens Morato; FAGÚNDEZ, Paulo Roney Ávila. Biossegurança e novas tecnologias na sociedade de risco: aspectos jurídicos, técnicos e sociais. Florianópolis: Conceito Editorial, 2007. p. 71-90.

DINIZ, M. H. Curso de direito civil brasileiro. 19. ed. São Paulo: Saraiva. 2005. v. 7 .

DOUGLAS, M. La aceptabilidad del riesgo según las ciencias sociales. Barcelona: Paidós Studio, 1996.

GAGLIANO, P. S.; PAMPLONA FILHO, R. Novo curso de direito civil: responsabilidade civil. São Paulo: Saraiva, 2003.

GIORGI, R. de. Direito, democracia e risco: vínculos com o futuro. Porto Alegre: Sérgio Fabris Editor, 1998.

HENKES, S. L. As decisões político-jurídicas frente à crise hídrica e aos riscos: lições e contradições da transposição do rio São Francisco. Florianópolis, 2008. 451 f. Tese (Doutorado) - Universidade Federal de Santa Catarina, Centro de Ciências Jurídicas. Programa de Pós-Graduação em Direito.

LEITE, J. R. M. Dano ambiental: do individual ao coletivo extrapatrimonial. 2. ed. São Paulo: Ed. Revista dos Tribunais, 2003.

; AYALA, P. de A. Direito ambiental na sociedade de risco. 2. ed. Rio de Janeiro: Forense Universitária, 2004.

LUHMANN, N. Sociología del riesgo. Cidade do México: Triana Editores, 1998.

MELLO, C. A. B. de. Curso de direito administrativo. 14. ed. São Paulo: MaIheiros Ed., 2002.

MIRRA, Á. L. V. Ação civil pública e a reparação do dano ao meio ambiente. 2. ed. São Paulo: Juarez de Oliveira, 2002.

NORONHA, F. Desenvolvimentos contemporâneos da responsabilidade civil. Revista dos Tribunais, São Paulo, v. 761, p. 37-38, 1999.

NUCCI, G. de S. Manual de direito penal. São Paulo: Ed. Revista dos Tribunais, 2007.

OUDOT, P. Le risque de développement: contribution au mantien du droit à reparation. Dijon: Éditions Universitaires de Dijon, 2005.

SANSEVERINO, P. de T. Fundamentos da responsabilidade civil. 2008. 46 p. Datilografado.

STEIGLEDER, A. M. Responsabilidade civil ambiental: as dimensões do dano ambiental no direito brasileiro. Porto Alegre: Livraria do Advogado, 2004.

WATEL, P. P. Sociologie du risque. Paris: Armand Colin, 2003. 